\title{
Detailed Behavior Analysis for High Voltage Bidirectional Flyback Converter Driving
} DEAP Actuator

\author{
Huang, Lina; Zhang, Zhe; Andersen, Michael A. E.
}

Published in:

Proceedings of IECON 2013)

Publication date:

2013

Link back to DTU Orbit

Citation (APA):

Huang, L., Zhang, Z., \& Andersen, M. A. E. (2013). Detailed Behavior Analysis for High Voltage Bidirectional Flyback Converter Driving DEAP Actuator. In Proceedings of IECON 2013) IEEE.

\section{General rights}

Copyright and moral rights for the publications made accessible in the public portal are retained by the authors and/or other copyright owners and it is a condition of accessing publications that users recognise and abide by the legal requirements associated with these rights.

- Users may download and print one copy of any publication from the public portal for the purpose of private study or research.

- You may not further distribute the material or use it for any profit-making activity or commercial gain

- You may freely distribute the URL identifying the publication in the public portal

If you believe that this document breaches copyright please contact us providing details, and we will remove access to the work immediately and investigate your claim. 


\title{
Detailed Behavior Analysis for High Voltage Bidirectional Flyback Converter Driving DEAP Actuator
}

\author{
Lina Huang, Zhe Zhang, Michael A. E. Andersen \\ Technical University of Denmark, Oersteds Plads, Building 349, Kgs. Lyngby, Denmark \\ huang@elektro.dtu.dk, zz@elektro.dtu.dk, ma@elektro.dtu.dk
}

\begin{abstract}
DEAP (Dielectric Electro Active Polymer) is a new type of smart material. The tubular actuator based on DEAP material has various potential applications and is fundamentally a capacitive load. A high voltage bidirectional converter is required to provide power for the actuator. A bidirectional flyback based converter has been implemented. The parasitic elements have serious influence for the operation of the converter, especially in the high output voltage condition. The detailed behavior analysis has been performed considering the impact of the critical parasitic parameters. The converter has been analyzed for both charging and discharging processes in low and high output voltage operating occasions. The experimental waveforms can validate the analysis.
\end{abstract}

Keywords-DEAP actuator; bidirectional; flyback; high voltage; behavior analysis

\section{INTRODUCTION}

As a smart material, DEAP (Dielectric Electro Active Polymer) material started to receive increasing attention among scientists and engineers since early 1990s [1], [2]. DEAP material possesses simple structure - a thin dielectric elastomer sheet sandwiched between two compliant electrodes [2]. Because of the electrostatic pressure, the elastomer is compressed in the thickness direction and expands in the transverse direction by applying voltage to the electrodes [1], [2]. This actuation property makes it possible to develop DEAP material based actuator. In addition, the same construction as capacitor enables the DEAP to be represented by a plate capacitor whose values changes with the geometry [1], [3]. Hence, DEAP has the potential to work as a sensor when applied mechanical or electrical force changes its capacitance. Further, DEAP is a good alternative over other smart materials in the application of energy harvesting [3].

Taking the advantage of light weight, noiseless operation, large strain, high energy density, fast speed of response and high efficiency, DEAP actuators can be a promising replacement for conventional actuators as well as other smart material based actuators [1], [2], [3]. Numerous potential or conceptual applications have already been proposed by material or mechanical researchers in the field of biomimetics, micro electro mechanical systems (MEMS), acoustics, etc. Correspondingly, a variety of configurations is continuously emerging, such as the unimorph, bimorph, diaphragm, tube and roll constructions [1], [2].
Much research concerning DEAP tends to concentrate on the understanding and improvement of the polymer materials as well as the implementation of different configured DEAP actuators in various potential applications. However, not much research related to the development of driving converters for DEAP actuators has been carried out, especially for the driving devices with small size, high efficiency as well as low cost [4]. The object of this paper is to develop a bidirectional flyback based converter in order to drive DEAP actuator and perform a detailed behavior analysis for the operation of this high voltage converter.

This paper is organized as follows. Part II discusses the characteristics of tubular DEAP actuator. Part III addresses the implementation of a low input voltage high output voltage DC-DC driving converter. The corresponding operation behaviors are detailedly analyzed in Part IV. Finally, we make a conclusion in Part V.

\section{CHARACTERISTICS OF TUBULAR DEAP ACTUATOR}

With a simple configuration, tubular DEAP actuator, shown in Fig. 1, can be applied in a variety of occasions and has attracted considerable concern among researchers [4], [5]. To

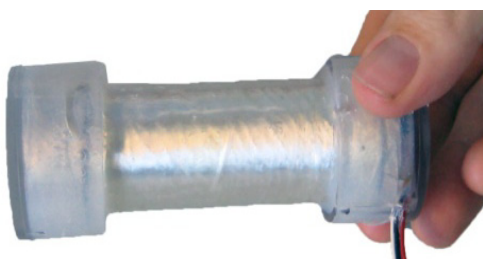

Fig. 1. Tubular DEAP actuator.

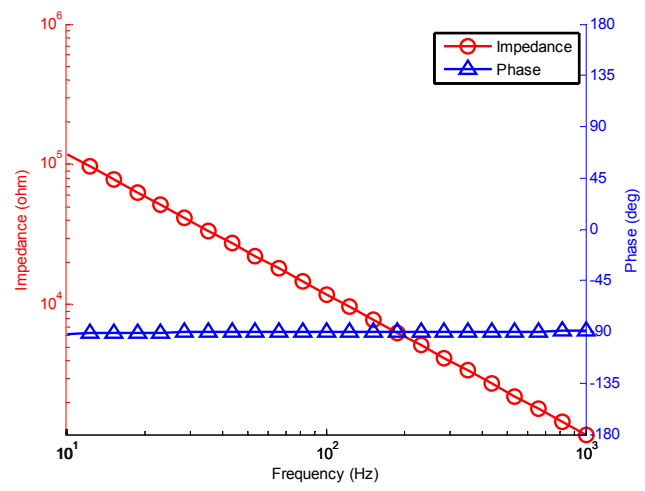

Fig. 2. Impedance versus frequency characteristic of tubular DEAP actuator. 
have a better understanding of the characteristics of tubular DEAP actuator is beneficial to design desirable stimulating circuits. Firstly, the impedance versus frequency characteristic is measured using N4L PSM1735 frequency response analyzer with its impedance analysis interface, shown in Fig. 2. The $90^{\circ}$ phase angle indicates that the measured tubular DEAP actuator is purely capacitive.

In addition, the stroke and strain versus applied voltage characteristic can be obtained by numerically solving the equations based on [6]. The stroke stands for the absolute elongation distance while strain indicates the relative expansion compared to the initial length of actuator. Corresponding to around $1.8 \%$ strain, the maximum displacement $1.05 \mathrm{~mm}$ under $2.4 \mathrm{kV}$ implies it is necessary to fully elongate the actuator with a high voltage driving device.

Further, previous research has been performed to validate the capacitance change versus voltage characteristic [7]. According to [7], the capacitance versus strain relationship can be expressed in (1), where $C_{0}$ is the capacitance of unstrained actuator and $s$ corresponds to the strain of the actuator.

$$
C=C_{0} \cdot(1+s)^{1.83}
$$

Together with the strain versus voltage property, we can obtain the capacitance change versus voltage characteristic. Maximum 3.2\% capacitance change under $2.4 \mathrm{kV}$ makes it reasonable to assume this tubular DEAP actuator to be a capacitor with constant value. This assumption tends to simplify the consideration concerning the load when designing the driving circuits.

Moreover, the electrical to mechanical efficiency has been discussed and measured in [8]. The low energy conversion ratio indicates that most electrical energy must be stored in the capacitive actuator. Therefore, a high voltage driving converter with the ability to recover the energy back to the power source is beneficial to improve the overall energy utilization ratio [1], [8].

\section{IMPLEMENTATION OF HIGH VOLTAGE BIDIRECTIONAL CONVERTER}

In general, autonomous actuation system tends to be preferable in the case of biomimetic and MEMS applications. Batteries are more likely to be the principle energy source in these situations. A $3 \mathrm{~V}$ battery powered driving converter has been proposed to implement in order to charge a DEAP actuator with $220 \mathrm{nF}$ capacitance to $2.4 \mathrm{kV}$ and discharge to 0 $\mathrm{V}$. The designed power stage of bidirectional flyback converter is shown in Fig. 3. In addition, some critical parasitic elements are depicted as well, which will be used in the detailed behavior analysis later. In fact, the primary and secondary leakage inductors cannot exist at the same time. When energy flow is from power source to secondary side, we use primary leakage inductor to describe the untransferable energy stored in flyback transformer, and vice versa. Two capacitor charger controllers LT3750 from Linear Technology are employed to implement the control for the flyback converter. One is used to realize the charge control for the capacitive load and the discharge control is achieved through the other one. The converter has been built and the picture is shown in Fig. 4. The symbols shown in Fig. 3 and other critical parameters which will be utilized in the following analysis have been addressed in Table I with the values.

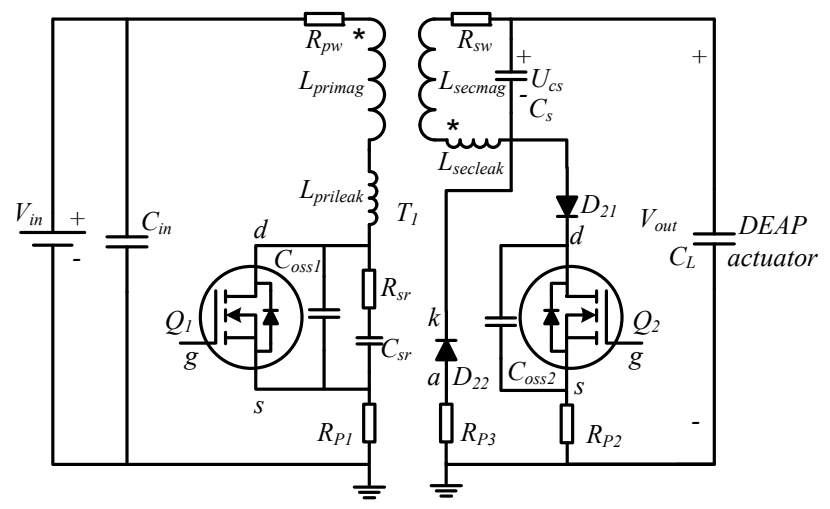

Fig. 3. Schematic of the power stage of bidirectional flyback converter.

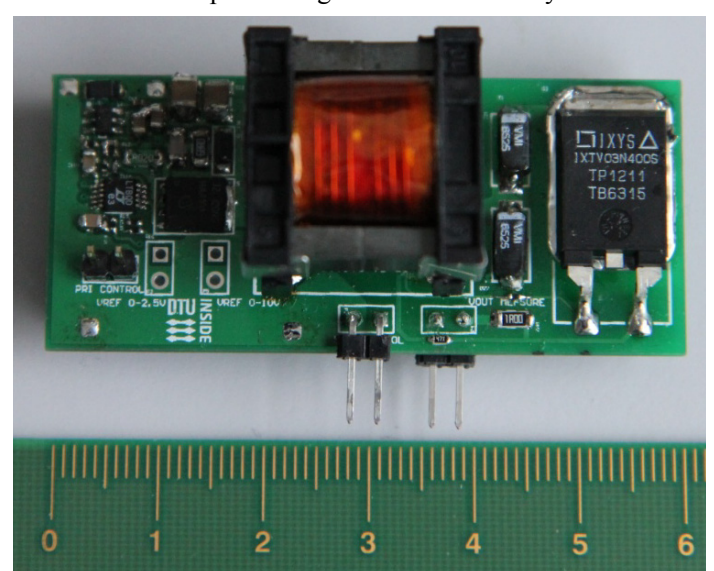

Fig. 4. Picture for the high voltage bidirectional converter.

TABLE I. High VOLTAGE BidireCtiONAL FLYBACK CONVERTER PARAMETER DEFINITIONS AND VALUES

\begin{tabular}{|c|c|c|}
\hline Symbols & Parameters & Values \\
\hline$L_{\text {primag }}$ & Primary magnetizing inductance & $13 \mu \mathrm{H}$ \\
\hline$L_{\text {prileak }}$ & Primary leakage inductance & $300 \mathrm{nH}$ \\
\hline$L_{\text {secmag }}$ & Secondary magnetizing inductance & $18.85 \mathrm{mH}$ \\
\hline$L_{\text {secleak }}$ & Secondary leakage inductance & $450 \mu \mathrm{H}$ \\
\hline$C_{s}$ & $\begin{array}{l}\text { Secondary winding stray } \\
\text { capacitance }\end{array}$ & $14.2 \mathrm{pF}$ \\
\hline$R_{p w}$ & Primary AC resistance & $\begin{array}{r}79.4 \mathrm{~m} \Omega @ 1 \mathrm{kHz} \\
106.81 \mathrm{~m} \Omega @ 100 \mathrm{kHz}\end{array}$ \\
\hline$R_{s w}$ & Secondary AC resistance & $\begin{array}{c}4.99 \Omega @ 1 \mathrm{kHz} \\
29.92 \Omega @ 100 \mathrm{kHz}\end{array}$ \\
\hline$R_{d s o n Q 1}$ & $\begin{array}{l}Q_{l} \text { drain to source on-state } \\
\text { resistance }\end{array}$ & $27 \mathrm{~m} \Omega @ V_{G S}=10 \mathrm{~V}$ \\
\hline$C_{\text {oss } 1}$ & $Q_{1}$ output capacitor & $280 \mathrm{pF} @ V_{D S}=40 \mathrm{~V}$ \\
\hline$V_{b d Q 1}$ & $Q_{1}$ body diode forward voltage & $0.7 \mathrm{~V} @ I_{F}=4 \mathrm{~A}$ \\
\hline$R_{d s o n Q 2}$ & $\begin{array}{c}Q_{2} \text { drain to source on-state } \\
\text { resistance }\end{array}$ & $\leq 290 \Omega$ \\
\hline$C_{\text {oss } 2}$ & Q2 output capacitor & $19 \mathrm{pF} @ V_{D S}=2 \mathrm{~V}$ \\
\hline$V_{d 21} V_{d 22}$ & $\begin{array}{l}\text { High voltage diode } \\
\text { forward voltage }\end{array}$ & $7 \mathrm{~V} @ I_{F}=150 \mathrm{~mA}$ \\
\hline$R_{P 1}$ & Primary current sensing resistor & $20 \mathrm{~m} \Omega$ \\
\hline$R_{P 2} R_{P 3}$ & Secondary current sensing resistor & $1 \Omega$ \\
\hline$C_{s r}$ & Primary snubber capacitor & $220 \mathrm{pF}$ \\
\hline$R_{s r}$ & Primary snubber resistor & $68 \Omega$ \\
\hline$C_{L}$ & Capacitive load & $220 \mathrm{nF}$ \\
\hline Vin & Input voltage & $3 \mathrm{~V}$ \\
\hline$N$ & $\begin{array}{c}\text { Turns ratio } \\
\text { (secondary turns/primary turns) }\end{array}$ & $232 / 6$ \\
\hline$I_{\text {pripeak }}$ & Primary peak current & $4 \mathrm{~A}$ \\
\hline$I_{\text {secpeak }}$ & Secondary peak current & $103 \mathrm{~mA}$ \\
\hline
\end{tabular}




\section{DETAILED BEHAVIOR ANALYSIS OF HIGH VOLTAGE BIDIRECTIONAL FLYBACK CONVERTER AND EXPERIMENTAL VALIDATION}

Considering the critical parasitic parameters shown in Fig. 3, a detailed behavior analysis has been performed. The converter is analyzed according to the charging and discharging process respectively. In order to verify the analysis and compare analyzed results with experimental ones, the experiments have been performed and the waveforms are shown beside the analyzed waveforms.

\section{A. Charging process}

The analyzed model has been built for one single charging cycle, which is applicable for any cycle in the charging process. In fact, the analysis can be carried out based on five different time intervals. In each interval, we create model to mimic the critical behavior of the converter. For certain charging cycle, the initial output voltage is represented as $V_{\text {outnitial }}$, which is the starting condition for the current cycle.

$\left[\mathrm{t}_{0}-\mathrm{t}_{1}\right]$ : In this period, secondary winding stray capacitor resonates with the secondary inductance until primary MOSFET is switched on. As another point of view, the initial energy stored in $C_{s}$ oscillates between $C_{s}$ and $L_{\text {secmag }}+L_{\text {secleak }}$. Considering the effect of $R_{s w}$, the voltage over $C_{s}$ can be obtained through solving (2) with the initial conditions in (3).

$$
\begin{aligned}
& \left(L_{\text {secmag }}+L_{\text {secleak }}\right) \cdot C_{S} \cdot \frac{d U_{c S}^{2}\left(t-t_{0}\right)}{d^{2}\left(t-t_{0}\right)}+R_{S w} \cdot C_{s} \cdot \frac{d U_{c S}\left(t-t_{0}\right)}{d\left(t-t_{0}\right)}+ \\
& U_{c S}\left(t-t_{0}\right)=0 \\
& \left\{\begin{array}{c}
\left.U_{c S}\left(t-t_{0}\right)\right|_{t=t_{0}}=V_{\text {outInitial }}+V_{d 22} \\
\left.\frac{d U_{c S}\left(t-t_{0}\right)}{d\left(t-t_{0}\right)}\right|_{t=t_{0}}=0
\end{array}\right.
\end{aligned}
$$

After obtaining $U_{c s}\left(t-t_{0}\right)$, the current through $C_{s}$ can be solved through (4).

$$
I_{C S}\left(t-t_{0}\right)=C_{s} \cdot \frac{d U_{C S}\left(t-t_{0}\right)}{d\left(t-t_{0}\right)}
$$

In practice, the terminal condition in this stage for low output voltage operation is different from high voltage operation. $Q_{1}$ is switched on when $U_{c s}\left(t-t_{0}\right)$ reaches the minimum value due to the primary controller for low output voltage. Therefore, half the resonance period can be used to calculate the time interval, represented in (5).

$$
t_{1}=t_{0}+\pi \cdot \sqrt{L_{\text {sec }} \cdot C_{s}}
$$

For high voltage operation, when $U_{c s}\left(t-t_{0}\right)$ reaches $N \cdot\left(V_{i n}+V_{b d Q I}\right)$, the body diode of $Q_{l}$ is forced to conduct first, afterwards, $Q_{1}$ is switched on. In fact, compared with time interval $\left[\mathrm{t}_{1}-\mathrm{t}_{3}\right]\left(Q_{l}\right.$ on time), the body diode only conducts for so short time that we can assume $Q_{1}$ is switched on at exact $\mathrm{t}_{1}$ to simplify the analysis. Hence, the time interval can be calculated through solving (6). The switchover point from low to high voltage operation is when (6) has solution and happens around when $V_{\text {outInitial }}+V_{d 22}$ reaches $N \cdot\left(V_{i n}+V_{b d Q 1}\right)$.

$$
\left.U_{c s}\left(t-t_{0}\right)\right|_{t=t_{1}}=-N \cdot\left(V_{i n}+V_{b d Q 1}\right)
$$

With the solved time interval and (2), we can predict the essential behavior in this stage. However, it must be clarified that this stage does not exist for the first charging cycle due to the energy stored in $C_{s}$ is 0 at the start. $\left[\mathrm{t}_{1}-\mathrm{t}_{2}\right]$ : The analysis for this period needs to be divided into low and high output voltage as well. According to [9], in the low voltage operation, $V_{\text {in }}$ starts to magnetize the primary inductance, meanwhile, $U_{c s}$ is charged to $-V_{i n} \cdot N$ through the resonance between the $L_{\text {prileak }}$ and the reflected capacitance of $C_{S}+C_{\text {oss } 2}$ in the primary side. Due to $D_{21}$, the actual behavior is much more complex, we assume $C_{\text {oss } 2}$ is in parallel with $C_{s}$ in order to simplify the model. In this short period, we only consider the resonance and leave the calculation concerning magnetization to the whole $\left[\mathrm{t}_{1}-\mathrm{t}_{3}\right]$ period later. Therefore, $U_{c s}\left(t-t_{l}\right)$ can be obtained through solving (7) under the initial conditions in (8).

$$
\begin{array}{r}
L_{\text {prileak }} \cdot N^{2} \cdot\left(C_{s}+C_{o s s 2}\right) \cdot\left(-\frac{d U_{c S}^{2}\left(t-t_{1}\right)}{d^{2}\left(t-t_{1}\right)}\right)+\left(R_{d s o n Q 1}+\right. \\
\left.R_{P 1}+\frac{R_{s w}}{N^{2}}\right) \cdot N^{2} \cdot\left(C_{s}+C_{o s s 2}\right) \cdot \frac{d U_{c S}\left(t-t_{1}\right)}{d\left(t-t_{1}\right)}-\frac{U_{c s}\left(t-t_{1}\right)}{N}=V_{i n}(7) \\
\left\{\begin{array}{c}
\left.U_{c s}\left(t-t_{1}\right)\right|_{t=t_{1}}=\left.U_{c s}\left(t-t_{0}\right)\right|_{t=t_{1}=t_{0}+\pi \cdot \sqrt{L_{s e c} \cdot C_{s}}} \\
\left.\frac{d U_{c s}\left(t-t_{1}\right)}{d\left(t-t_{1}\right)}\right|_{t=t_{1}}=0
\end{array}\right.
\end{array}
$$

After deriving $U_{c s}\left(t-t_{1}\right)$, the current through $C_{s}$ can be solved through (9).

$$
I_{c s}\left(t-t_{1}\right)=\left(C_{s}+C_{o s s}\right) \cdot \frac{d U_{c s}\left(t-t_{1}\right)}{d\left(t-t_{1}\right)}
$$

For high voltage operation, at the end of period $\left[\mathrm{t}_{0}-\mathrm{t}_{1}\right]$, the body diode in $Q_{l}$ starts to conduct in order to transfer the energy stored in flyback transformer to primary power source. Owing to the energy stored in $L_{\text {secleak }}$, the resonance between $L_{\text {secleak }}$ and $\left(C_{s}+C_{\text {oss } 2}\right)$ takes place in $\left[\mathrm{t}_{1}-\mathrm{t}_{2}\right]$. Therefore, the similar equation as (7) can be derived to acquire $U_{c s}$ for high voltage operation. However, the initial conditions are different, which are represented in (10).

$$
\left\{\begin{array}{c}
\left.U_{c S}\left(t-t_{1}\right)\right|_{t=t_{1}}=\left.U_{c S}\left(t-t_{0}\right)\right|_{t=t_{1}}=-N \cdot\left(V_{i n}+V_{b d Q 1}\right) \\
\left.\frac{d U_{c S}\left(t-t_{1}\right)}{d\left(t-t_{1}\right)}\right|_{t=t_{1}}=\left.\frac{d U_{c S}\left(t-t_{0}\right)}{d\left(t-t_{0}\right)}\right|_{t=t_{1}}
\end{array}\right.
$$

$\left[\mathrm{t}_{1}-\mathrm{t}_{3}\right]$ : This stage is the on time for $Q_{l}$. The current through $L_{\text {secmag }}$ can be obtained through solving (11).

$$
\begin{aligned}
& \left(L_{\text {primag }}+L_{\text {prileak }}\right) \cdot \frac{d I_{\text {primag }}\left(t-t_{1}\right)}{d\left(t-t_{1}\right)}+\left(R_{\text {dsonQ } 1}+R_{P 1}+\right. \\
& \left.R_{\text {pw }}\right) \cdot I_{\text {primag }}\left(t-t_{1}\right)=V_{\text {in }}
\end{aligned}
$$

The initial current for $I_{\text {primag }}$ in the low voltage operation is 0 , however, the current starts from a minus value for high output voltage, which is represented in (12).

$$
\left.I_{\text {primag }}\left(t-t_{1}\right)\right|_{t=t_{1}}=\left.N \cdot I_{c s}\left(t-t_{0}\right)\right|_{t=t_{1}}
$$

Because of the fixed peak current control, the time interval for this stage can be acquired by solving (13).

$$
\left.I_{\text {primag }}\left(t-t_{1}\right)\right|_{t=t_{3}}=I_{\text {pripeak }}
$$

Combining the resonance in $\left[\mathrm{t}_{1}-\mathrm{t}_{2}\right]$ and the magnetizing equations for $\left[t_{1}-t_{3}\right]$, we can build the model to mimic the behavior in the whole $\left[t_{1}-t_{3}\right]$ period.

$\left[\mathrm{t}_{3}-\mathrm{t}_{4}\right]:$ At $\mathrm{t}_{3}, Q_{1}$ is switched off. Due to the influence of $C_{s}, D_{22}$ cannot conduct when $Q_{1}$ is just turned off. The energy stored in flyback transformer needs to charge $C_{s}$ until $U_{c s}$ reaches $V_{\text {outInitial }}+V_{d 22}$. The time interval $\left[\mathrm{t}_{3}-\mathrm{t}_{4}\right]$ is used to express this behavior. Replacing $L_{\text {secmag }}+L_{\text {secleak }}$ with $L_{\text {secmag }}$ in (2), we can get the similar differential equation to calculate $U_{c s}$ in this period and the initial conditions are given in (14). 


$$
\left\{\begin{array}{l}
\left.U_{c s}\left(t-t_{3}\right)\right|_{t=t_{3}}=-N \cdot V_{\text {in }} \\
\left.\frac{d U_{c S}\left(t-t_{3}\right)}{d\left(t-t_{3}\right)}\right|_{t=t_{3}}=\frac{I_{\text {pripeak }}}{N}
\end{array}\right.
$$

The time interval can be obtained through solving (15) with the terminal condition $-U_{c s}$ reaches $V_{\text {outInitial }}+V_{d 22}$.

$$
\left.U_{c S}\left(t-t_{3}\right)\right|_{t=t_{4}}=V_{\text {outInitial }}+V_{d 22}
$$

The final current through $C_{s}$ in this period needs to be calculated as well, represented in (16), which is the actual initial freewheeling current for next time interval.

$$
I_{f \text { wnitial }}=\left.C_{s} \cdot \frac{d U_{c s}\left(t-t_{3}\right)}{d\left(t-t_{3}\right)}\right|_{t=t_{4}}
$$

This period can be neglected in the low voltage operation and tends to become more obvious with the increasing of the output voltage. In fact, when $Q_{l}$ is switched off, $L_{\text {prileak }}$ will resonate with $C_{o s s}$ and $C_{s r}$ to dissipate the stored energy. But this phenomenon only exists for a very short time even compared to the time interval $\left[t_{3}-t_{4}\right]$. Therefore, this resonance behavior has not been modelled. However, in the worst case, all the energy stored in $L_{\text {prileak }}$ is used to charge $C_{\text {oss }}$, what we need to do is to check the maximum voltage over $C_{\text {oss }}$ will not exceed the voltage rating of $Q_{1}$.

$\left[t_{4}-t_{5}\right]$ : This stage is used to release the energy stored in transformer to the capacitive load. The output voltage $V_{\text {out }}$ can be acquired by solving the differential equation in (17) with the initial conditions given in (18).

$$
\begin{aligned}
& L_{\text {secmag }} \cdot C_{L} \cdot \frac{d V_{\text {out }}^{2}\left(t-t_{4}\right)}{d^{2}\left(t-t_{4}\right)}+R_{\text {sw }} \cdot C_{L} \cdot \frac{d V_{\text {out }}\left(t-t_{4}\right)}{d\left(t-t_{4}\right)}+ \\
& V_{\text {out }}\left(t-t_{4}\right)+V_{d 22}=0
\end{aligned}
$$

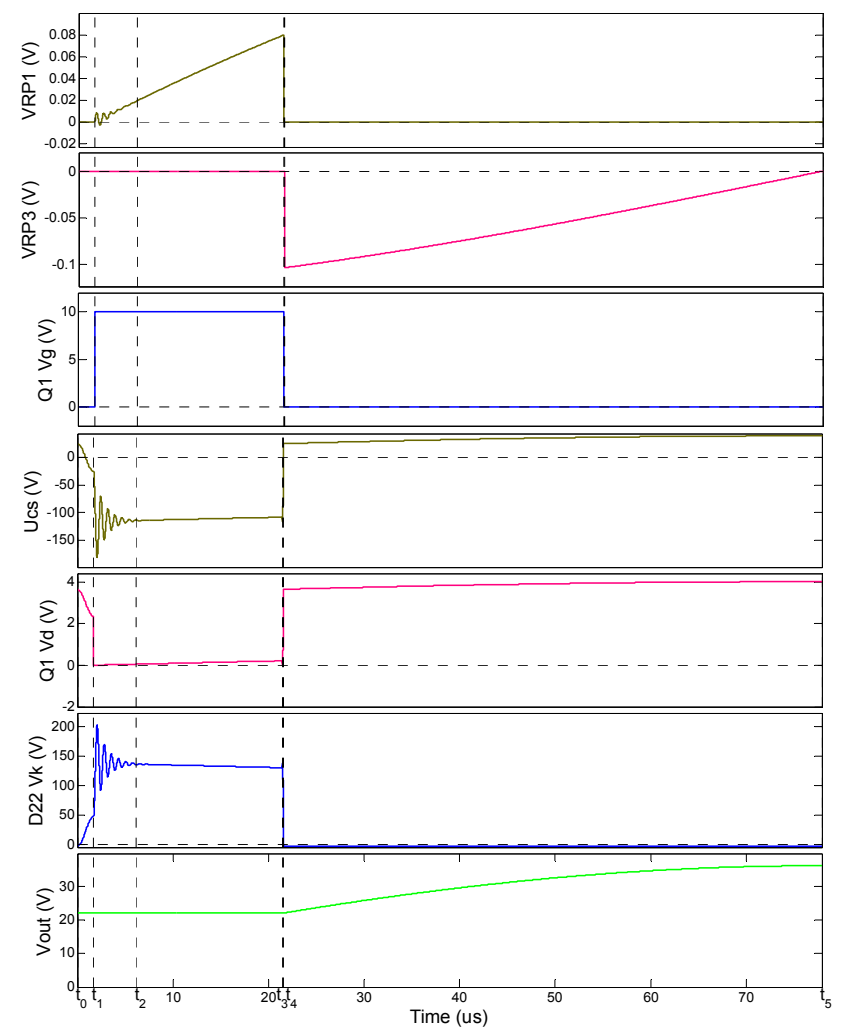

Fig. 5. Calculated critical waveforms of low output voltage operation in charging process.

$$
\left\{\begin{array}{c}
\left.V_{\text {out }}\left(t-t_{4}\right)\right|_{t=t_{4}}=V_{\text {outInitial }} \\
\left.\frac{d V_{\text {out }}\left(t-t_{4}\right)}{d\left(t-t_{4}\right)}\right|_{t=t_{4}}=\frac{I_{\text {fwInitial }}}{C_{L}}
\end{array}\right.
$$

In addition, the freewheeling current is given by

$$
I_{C L}\left(t-t_{4}\right)=C_{L} \cdot \frac{d V_{\text {out }}\left(t-t_{4}\right)}{d\left(t-t_{4}\right)}
$$

By solving (20), we can get the freewheeling time and calculate the final output voltage for this charging cycle.

$$
\left.I_{C L}\left(t-t_{4}\right)\right|_{t=t_{5}}=0
$$

Based on the analysis mentioned above, a Maple program has been completed to solve all the differential equations with initial conditions. The symbolic solutions have been exported to MATLAB for obtaining the critical waveforms of the converter. In order to validate the model, the calculated critical waveforms for low output voltage operation $\left(V_{\text {outlnitial }}=22 \mathrm{~V}\right)$ in the charging process are shown in Fig. 5 and compared with the corresponding experimental waveforms in Fig. 6 and 7. In addition, the calculated critical waveforms for high voltage operation $\left(V_{\text {outnitial }}=2000 \mathrm{~V}\right)$, shown in Fig. 8, are compared with the experimental waveforms in Fig. 9 and 10 as well. The good match can verify the analysis as well as the mathematical model.

\section{B. Discharging process}

Similarly, the analyzed models based on different time intervals and differential equations have been built for one single cycle in discharging process. And the initial output voltage is represented as $V_{\text {outnitial }}$ as well.

[ $\left.\mathrm{t}_{0}-\mathrm{t}_{1}\right]: Q_{2}$ is switched on in this period. The energy in the capacitive load starts to magnetize flyback transformer until secondary current reaches the preset peak value. The output voltage can be obtained through solving similar differential equation represented in (17) with initial conditions given in (21).

$$
\left\{\begin{array}{c}
\left.V_{\text {out }}\left(t-t_{0}\right)\right|_{t=t_{0}}=V_{\text {out Initial }} \\
\left.\frac{d V_{\text {out }}\left(t-t_{0}\right)}{d\left(t-t_{0}\right)}\right|_{t=t_{0}}=0
\end{array}\right.
$$

Through similar equation as (4), we can calculate the secondary current $I_{\text {sec }}\left(t-t_{0}\right)$. Then the time interval can be

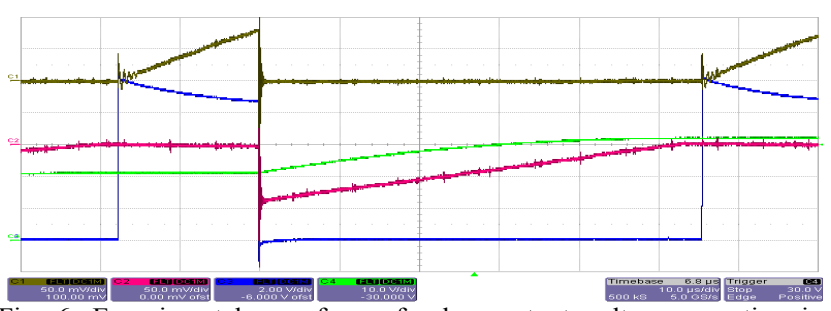

Fig. 6. Experimental waveforms for low output voltage operation in charging process $\left(\mathrm{CH} 1-\mathrm{V}_{\mathrm{RP} 1} \mathrm{CH} 2-\mathrm{V}_{\mathrm{RP} 3} \mathrm{CH} 3-\mathrm{Q}_{1} \mathrm{~V}_{\mathrm{g}} \mathrm{CH} 4-\mathrm{V}_{\text {out }}\right)$.

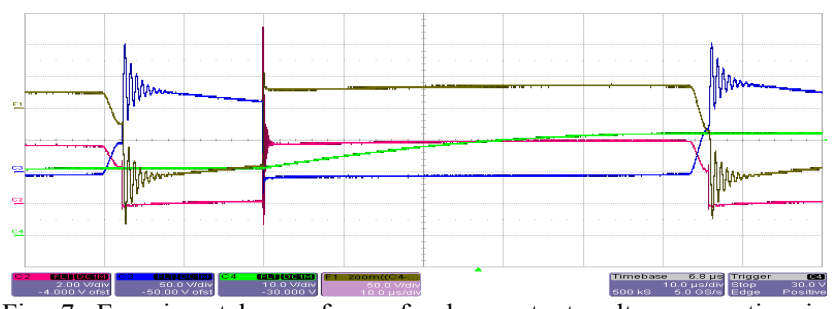

Fig. 7. Experimental waveforms for low output voltage operation in charging process (F1- $\mathrm{U}_{\mathrm{cs}} \mathrm{CH} 2-\mathrm{Q}_{1} \mathrm{~V}_{\mathrm{d}} \mathrm{CH} 3-\mathrm{D}_{22} \mathrm{~V}_{\mathrm{k}} \mathrm{CH} 4-\mathrm{V}_{\text {out }}$ ). 


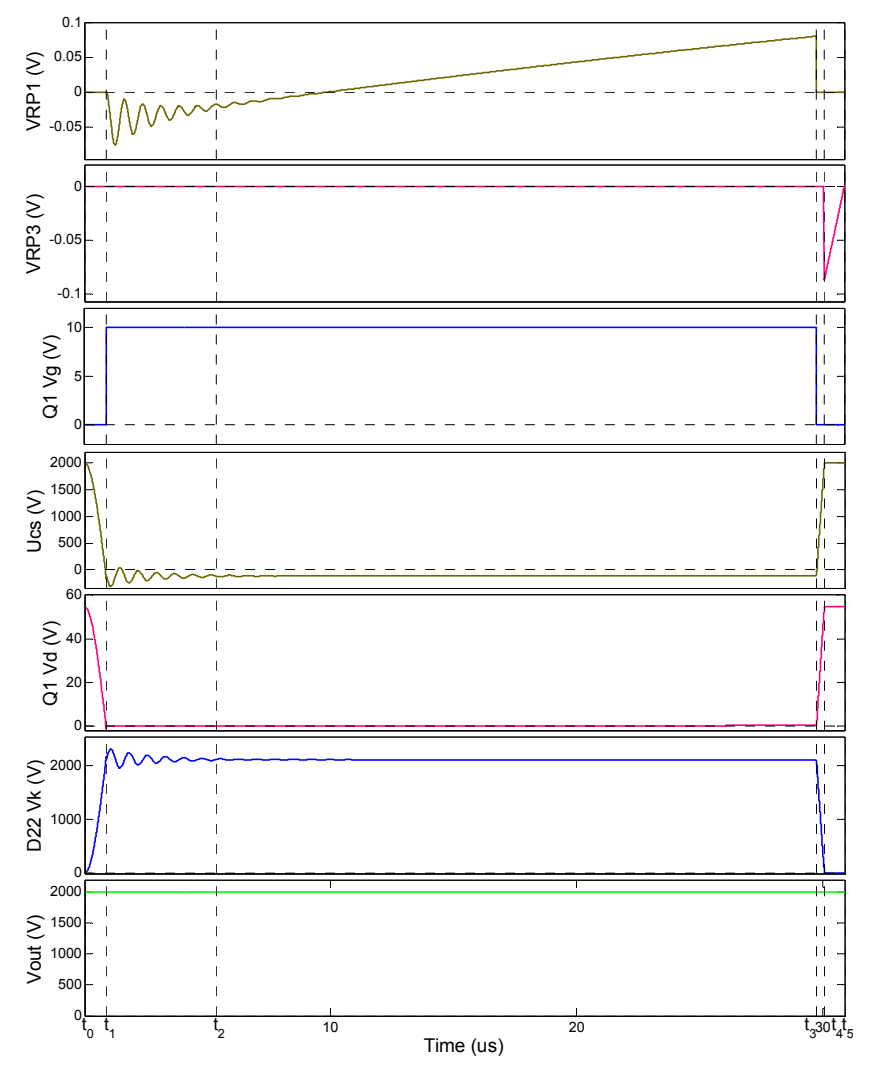

Fig. 8. Calculated critical waveforms of high output voltage operation in charging process.

acquired with analogical equation represented in (13), with which the final output voltage $V_{\text {outFinal }}$ can be determined.

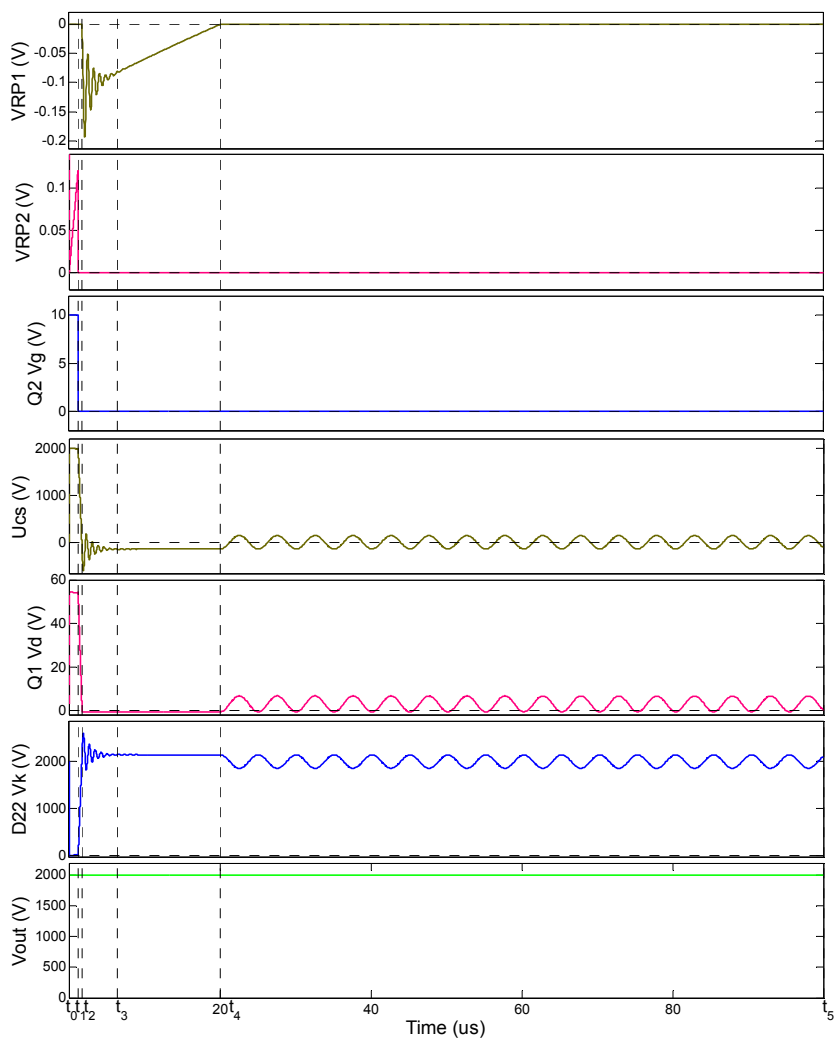

Fig. 11. Calculated critical waveforms of high output voltage operation in charging process.

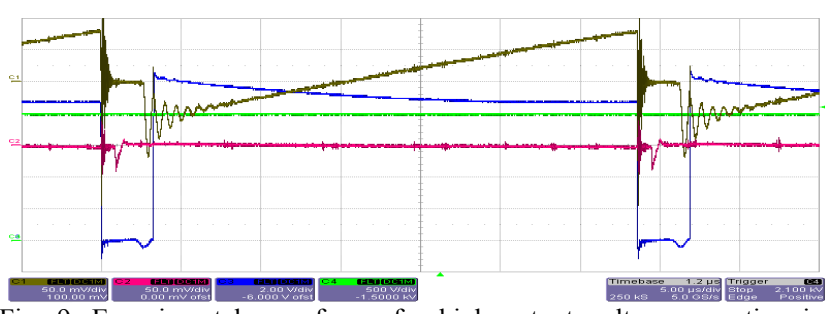

Fig. 9. Experimental waveforms for high output voltage operation in charging process $\left(\mathrm{CH} 1-\mathrm{V}_{\mathrm{RP} 1} \mathrm{CH} 2-\mathrm{V}_{\mathrm{RP} 3} \mathrm{CH} 3-\mathrm{Q}_{1} \mathrm{~V}_{\mathrm{g}} \mathrm{CH} 4-\mathrm{V}_{\text {out }}\right)$.

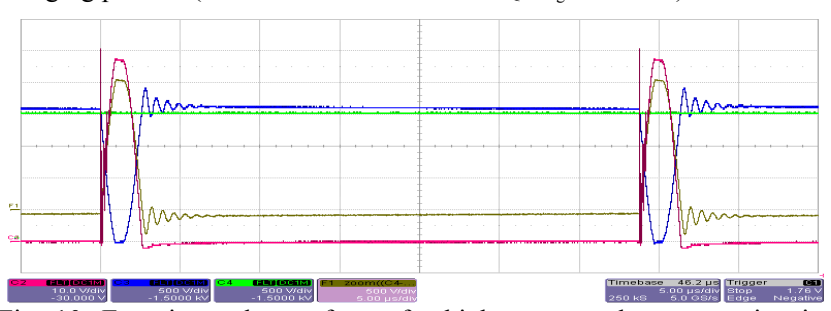

Fig. 10. Experimental waveforms for high output voltage operation in charging process $\left(\mathrm{F} 1-\mathrm{U}_{\mathrm{cs}} \mathrm{CH} 2-\mathrm{Q}_{1} \mathrm{~V}_{\mathrm{d}} \mathrm{CH} 3-\mathrm{D}_{22} \mathrm{~V}_{\mathrm{k}} \mathrm{CH} 4-\mathrm{V}_{\text {out }}\right)$.

$\left[\mathrm{t}_{1}-\mathrm{t}_{2}\right]: L_{\text {secmag }}+L_{\text {secleak }}$ resonate with $C_{s}+C_{\text {oss } 2}$ in this period until $U_{c s}$ reaches the $-N \cdot\left(V_{i n}+V_{b d Q I}\right)$. The behaviors are similar as $\left[\mathrm{t}_{0}-\mathrm{t}_{1}\right]$ in charging process. Hence, the similar equation as (2) can be derived to calculate $U_{c s}$ with the initial conditions represented in (22).

$$
\left\{\begin{array}{l}
\left.U_{c S}\left(t-t_{1}\right)\right|_{t=t_{1}}=V_{\text {outFinal }} \\
\left.\frac{d U_{C S}\left(t-t_{1}\right)}{d\left(t-t_{1}\right)}\right|_{t=t_{1}}=-\frac{I_{\text {secpeak }}}{C_{S}+C_{\text {oss } 2}}
\end{array}\right.
$$

$\left[\mathrm{t}_{2}-\mathrm{t}_{3}\right]: L_{\text {secleak }}$ resonate with $C_{s}+C_{\text {oss } 2}$ in this period until all the energy stored in $L_{\text {secleak }}$ dissipates. This stage has the similar behavior as $\left[\mathrm{t}_{1}-\mathrm{t}_{2}\right]$ in charging process. The analysis for high voltage operation in charging cycle is valid here and we can derive (23) to calculate $U_{c s}$ in this period with the initial conditions given in (24).

$$
\begin{aligned}
& L_{\text {secleak }} \cdot\left(C_{S}+C_{\text {oss } 2}\right) \cdot \frac{d U_{c S}^{2}\left(t-t_{2}\right)}{d^{2}\left(t-t_{2}\right)}+R_{s w} \cdot\left(C_{s}+C_{o s s 2}\right) \cdot \\
& \frac{d U_{c s}\left(t-t_{2}\right)}{d\left(t-t_{2}\right)}+U_{c S}\left(t-t_{2}\right)=0 \\
& \left\{\begin{array}{c}
\left.U_{c s}\left(t-t_{2}\right)\right|_{t=t_{2}}=\left.U_{c S}\left(t-t_{1}\right)\right|_{t=t_{2}} \\
\left.\frac{d U_{c S}\left(t-t_{2}\right)}{d\left(t-t_{2}\right)}\right|_{t=t_{2}}=\left.\frac{d U_{c s}\left(t-t_{1}\right)}{d\left(t-t_{1}\right)}\right|_{t=t_{2}}
\end{array}\right.
\end{aligned}
$$

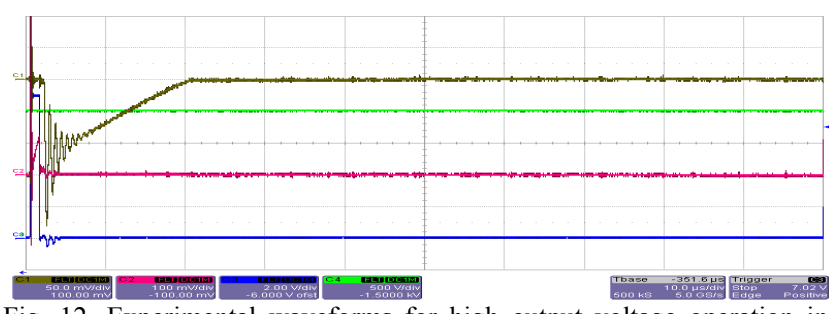

Fig. 12. Experimental waveforms for high output voltage operation in discharging process (CH1- $\left.\mathrm{V}_{\mathrm{RP} 1} \mathrm{CH} 2-\mathrm{V}_{\mathrm{RP} 2} \mathrm{CH} 3-\mathrm{Q}_{2} \mathrm{~V}_{\mathrm{g}} \mathrm{CH} 4-\mathrm{V}_{\text {out }}\right)$.

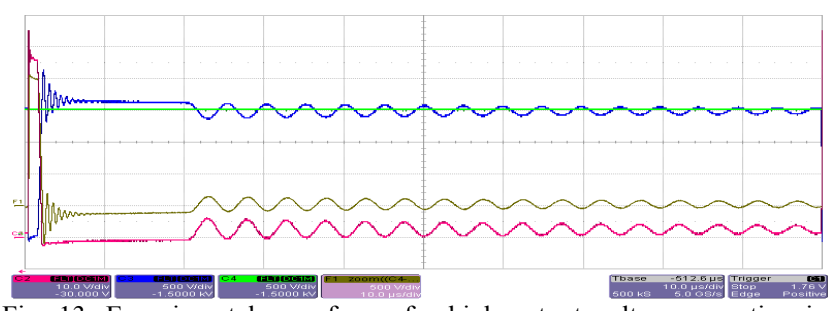

Fig. 13. Experimental waveforms for high output voltage operation in discharging process $\left(\mathrm{F} 1-\mathrm{U}_{\mathrm{cs}} \mathrm{CH} 2-\mathrm{Q}_{1} \mathrm{~V}_{\mathrm{d}} \mathrm{CH} 3-\mathrm{D}_{22} \mathrm{~V}_{\mathrm{k}} \mathrm{CH} 4-\mathrm{V}_{\text {out }}\right)$. 


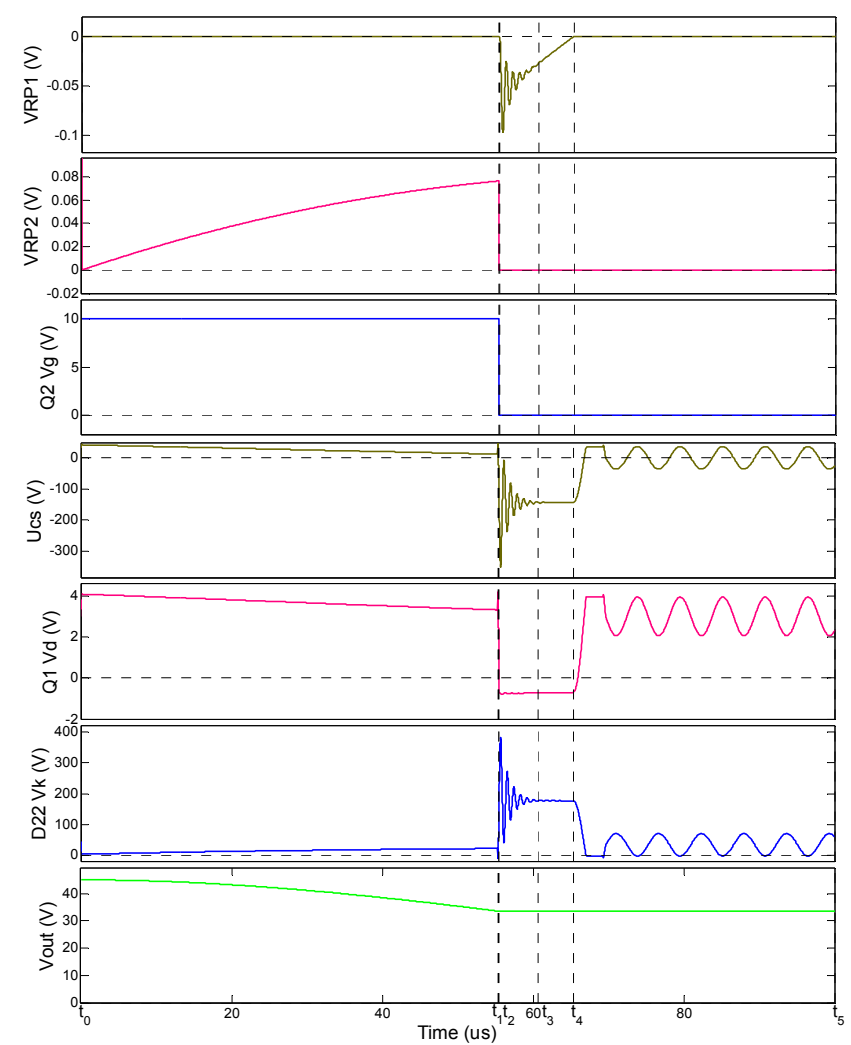

Fig. 14. Calculated critical waveforms of low output voltage operation in charging process.

$\left[t_{2}-t_{4}\right]$ : In this whole period, the energy stored in flyback transformer is transferred to primary power source through body diode of $Q_{l}$. Similar behaviors occur in stage [ $\left.\mathrm{t}_{1}-\mathrm{t}_{3}\right]$ of charging cycle. The derived equation (11) can be applied here with minor changes.

$\left[\mathrm{t}_{4}-\mathrm{t}_{5}\right]$ : This is the discontinuous conduction mode period in discharging cycle. $C_{s}$ as well as $C_{\text {oss } 2}$ will resonate with $L_{\text {secmag }}+L_{\text {secleak }}$ until the start of next cycle. In the high voltage operation, the voltage across $C_{s}$ can be acquired by solving differential equation (25) with initial conditions in (26).

$$
\begin{gathered}
\left(L_{\text {secmag }}+L_{\text {secleak }}\right) \cdot\left(C_{s}+C_{\text {oss } 2}\right) \cdot \frac{d U_{c S}^{2}\left(t-t_{4}\right)}{d^{2}\left(t-t_{4}\right)}+R_{s w} \\
\left(C_{s}+C_{o s s 2}\right) \cdot \frac{d U_{c S}\left(t-t_{4}\right)}{d\left(t-t_{4}\right)}+U_{c s}\left(t-t_{4}\right)=0 \\
\left\{\begin{array}{c}
\left.U_{c s}\left(t-t_{4}\right)\right|_{t=t_{4}}=\left.U_{c s}\left(t-t_{2}\right)\right|_{t=t_{4}} \\
\left.\frac{d U_{c s}\left(t-t_{4}\right)}{d\left(t-t_{4}\right)}\right|_{t=t_{4}}=0
\end{array}\right.
\end{gathered}
$$

For low output voltage operation, the behavior is more complex because the maximum resonance voltage over $C_{s}$ is clamped to $V_{\text {outFinal }}+V_{d 22}$. Similar with charging process, the switchover point occurs when $V_{\text {outFinal }}+V_{d 22}$ reaches $N \cdot\left(V_{i n}+V_{b d Q l}\right)$.

Another Maple program has been finished to solve all the differential equations for one discharging cycle and the solutions have been transferred to MATLAB in order to draw the critical waveforms as well. The calculated critical waveforms when $V_{\text {outtnitial }}=46 \mathrm{~V}$ and $V_{\text {out Initial }}=2000 \mathrm{~V}$ are shown in Fig. 11 and 14, respectively. The corresponding experimental waveforms, shown in Fig. 12, 13, 15 and 16, indicate the good match with calculated ones.

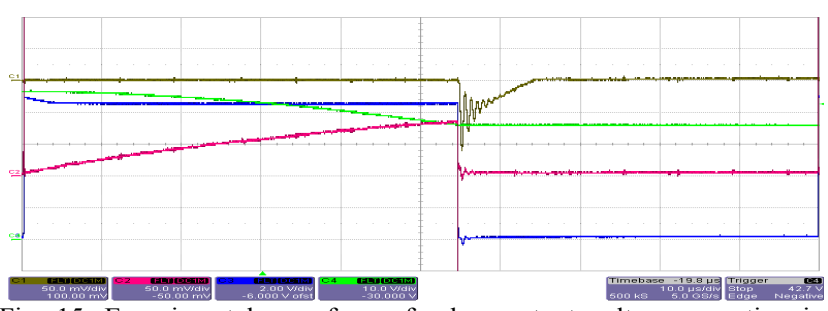

Fig. 15. Experimental waveforms for low output voltage operation in discharging process $\left(\mathrm{CH} 1-\mathrm{V}_{\mathrm{RP} 1} \mathrm{CH} 2-\mathrm{V}_{\mathrm{RP} 2} \mathrm{CH} 3-\mathrm{Q}_{2} \mathrm{~V}_{\mathrm{g}} \mathrm{CH} 4-\mathrm{V}_{\text {out }}\right)$.

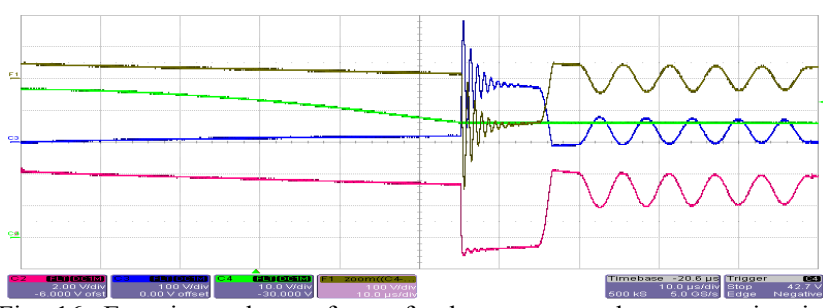

Fig. 16. Experimental waveforms for low output voltage operation in discharging process $\left(\mathrm{F} 1-\mathrm{U}_{\mathrm{cs}} \mathrm{CH} 2-\mathrm{Q}_{1} \mathrm{~V}_{\mathrm{d}} \mathrm{CH} 3-\mathrm{D}_{22} \mathrm{~V}_{\mathrm{k}} \mathrm{CH} 4-\mathrm{V}_{\text {out }}\right)$.

\section{CONCLUSION}

As a new type of smart material, DEAP material as well as DEAP based tubular actuator are introduced. The essential characteristics have been investigated. A low input voltage bidirectional flyback based converter for driving DEAP actuator has been implemented. The detailed behavior analysis considering the influence of the critical parasitic elements has been performed for the operation of the converter, including the analysis for both charging and discharging processes in the low and high output voltage conditions. The experimental results can provide a good proof for the analysis.

\section{REFERENCES}

[1] Y. Bar-Cohen, Electroactive Polymer (EAP) Actuators as Artificial Muscles: Reality, Potential, and Challenges, 2nd ed. Washington, DC: SPIE, 2004.

[2] R. Sarban, B. Lassen, and M Willatzen, "Dynamic electromechanical modeling of dielectric elastomer actuators with metallic electrodes," IEEE/ASME Transactions on Mechatronics, vol. 17, no. 5, pp. 960-967, October 2012

[3] Y. Iskandarani and H. R. Karimi, "Sensing capabilities based on dielectric electro active polymers - feasibility and potential state-of-theart application," IEEE Sensors Journal, vol. 12, no. 8, pp. 2616-2624, August 2012.

[4] L. Huang, Z. Zhang, and M. A. Andersen, "A review of high voltage drive amplifiers for capacitive actuators," 47th International Universities Power Engineering Conference (UPEC), 2012.

[5] T. Andersen, M. S. Rødgaard, O. C. Thomsen, and M. A. E. Andersen, "Low voltage driven dielectric electro active polymer actuator with integrated piezoelectric transformer based driver," SPIE, vol. 7976, pp. 79762N-1-79762N-12, 2011.

[6] R. Sarban, R. W. Jones, B. R. Mace and E. Rustighi, "A tubular dielectric elastomer actuator: Fabrication, characterization and active vibration isolation," Mechanical Systems and Signal Processing, vol. 25, pp. 2879-2891, 2011.

[7] T. Andersen, L. Huang, M. Andersen, and O. Thomsen, "Efficiency of capacitively loaded converters," 38th Annual Conference on IEEE Industrial Electronics Society (IECON), pp, 368-373, 2012.

[8] M. J. Tryson, R. Sarban, and K. P. Lorenzen, "The dynamic properties of tubular DEAP actuators," Electroactive Polymer Actuators and Devices (EAPAD), vol. 7642, 2010.

[9] S.-K. Chung, "Transient characteristics of high-voltage flyback transformer operating in discontinuous conduction mode," IEE Electric Power Applications, vol. 151, no. 5, pp. 628-634, 2004. 